Western University

Scholarship@Western

Chemistry Publications

Chemistry Department

Winter 3-15-2017

\title{
Poly(ethyl glyoxylate)-Poly(ethylene oxide) Nanoparticles: Stimuli- Responsive Drug Release via End-to-End Polyglyoxylate Depolymerization
}

Bo Fan

Western University, bfan25@uwo.ca

Elizabeth Gillies

Western University, egillie@uwo.ca

Follow this and additional works at: https://ir.lib.uwo.ca/chempub

Part of the Medicinal-Pharmaceutical Chemistry Commons, and the Polymer Chemistry Commons

Citation of this paper:

Fan, Bo and Gillies, Elizabeth, "Poly(ethyl glyoxylate)-Poly(ethylene oxide) Nanoparticles: Stimuli- Responsive Drug Release via Endto-End Polyglyoxylate Depolymerization" (2017). Chemistry Publications. 96.

https://ir.lib.uwo.ca/chempub/96 


\title{
Poly(ethyl glyoxylate)-poly(ethylene oxide) nanoparticles: Stimuli-responsive drug release via end-to-end polyglyoxylate depolymerization
}

\author{
Bo Fan ${ }^{\dagger}$ and Elizabeth R. Gillies, ${ }^{\dagger *}$ \\ ${ }^{\dagger}$ Department of Chemical and Biochemical Engineering, The University of Western Ontario, \\ 1151 Richmond St., London, Ontario, Canada, N6A 5B9 \\ ${ }^{\sharp}$ Department of Chemistry, The University of Western Ontario, 1151 Richmond St., London, \\ Ontario, Canada, N6A 5B7
}

*Author to whom correspondence should be addressed: Elizabeth R. Gillies, Department of Chemistry, The University of Western Ontario, London, Ontario, Canada, N6G 1Z1; Email: egillie@uwo.ca; Phone: 519-661-2111 ext 80223; Fax: 519-661-3022 


\title{
Table of Contents Graphic
}

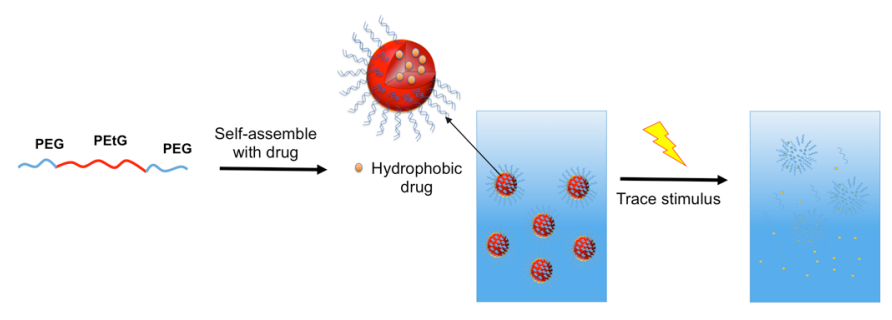

\begin{abstract}
The ability to disrupt polymer assemblies in response to specific stimuli provides the potential to release drugs selectivity at certain sites or conditions in vivo. However, most stimuli-responsive delivery systems require many stimuli-initiated events in order to release drugs.

"Self-immolative polymers" offer the potential to provide amplified responses to stimuli as they undergo complete end-to-end depolymerization following the cleavage of a single end-cap.

Herein, linker end-caps were developed to conjugate self-immolative poly(ethyl glyoxylate) (PEtG) with poly(ethylene oxide) (PEO) to form amphiphilic block copolymers. These copolymers were self-assembled to form nanoparticles in aqueous solution. Cleavage of the linker end-caps were triggered by a thiol reducing agent, UV light, $\mathrm{H}_{2} \mathrm{O}_{2}$, and combinations of these stimuli, resulting in nanoparticle disintegration. Low stimuli concentrations were effective in rapidly disrupting the nanoparticles. Nile red, doxorubin and curcumin were encapsulated into the nanoparticles and were selectively released upon application of the appropriate stimulus. The ability to tune the stimuli-responsiveness simply by changing the linker end-cap makes this new platform highly attractive for applications in drug delivery.
\end{abstract}




\section{Keywords}

Stimuli-responsive, depolymerization, self-immolative, drug delivery, polyglyoxylate

\section{Introduction}

Amphiphilic block copolymers can self-assemble in aqueous solution to form a wide range of

morphologies including spherical micelles, cylindrical micelles, and vesicles. ${ }^{1-3}$ Such assemblies have been of significant interest in recent years for the encapsulation and controlled release of drugs. $^{4-6}$ These delivery vehicles can enhance the water-dispersibility of hydrophobic drugs and selectively target them to sites of action such as tumors via the enhanced permeation and retention effect or using active targeting groups. ${ }^{7-9}$ Ideally, the assembly would be stable in the blood stream, but selectively release its payload at the target site. To achieve this, polymer assemblies responsive to the conditions associated with various disease states have been developed. For example, systems responsive to the acidic $\mathrm{pH}$ encountered in tumor tissue or within the endosomal compartments of cells have been introduced. ${ }^{10-13}$ Reducing conditions, associated with the intracellular environment and hypoxic tumor tissue, have also been used to disrupt polymer assemblies. ${ }^{14-16}$ Furthermore, polymer systems responsive to reactive oxygen species such as $\mathrm{H}_{2} \mathrm{O}_{2}$, associated with inflammation and cancer have also been developed. ${ }^{17,18}$ Most of these systems require the action of the stimulus at many sites along the polymer backbone in order to change the properties of the polymer, resulting in drug release. 
Over the past decade, a new class of degradable polymers that undergoes end-to-end depolymerization in response to the cleavage of a stimuli-responsive end-cap from the polymer terminus was introduced. Often termed "self-immolative polymers", these macromolecules require the action of a single stimulus to completely depolymerize the polymer. ${ }^{19-21}$ This provides the potential for signal amplification at low stimulus concentrations. End-caps responsive to stimuli such as light ${ }^{22-24}, \mathrm{H}_{2} \mathrm{O}_{2}{ }^{25,26}$, thiols ${ }^{24,27}$, and mildly acidic conditions ${ }^{28}$ have been reported and have been used in applications such as sensors ${ }^{25,29,30}$ and responsive coatings or plastics ${ }^{31-33}$. The incorporation of a second polymer block has provided amphiphilic copolymers that self-assembled to form nanoparticles such as micelles and vesicles. ${ }^{22,30,34}$ However, the potential of these systems for drug delivery has been explored only to a very limited extent. In addition, these examples involved depolymerization to species such as quinone methides and aza-quinone methides, which are likely toxic. ${ }^{35}$

Our group recently reported poly(ethyl glyoxylate) (PEtG) as a self-immolative polymer. ${ }^{22,28,33}$ As shown in Figure 1, the depolymerization products are ultimately ethanol and glyoxylic acid, a metabolic intermediate that can be processed in the liver. ${ }^{36}$ Studies have suggested that this degradation product should exhibit low toxicity both to mammals and the environment, ${ }^{37}$ making PEtG a promising polymer for drug delivery and other applications. Using a UV light-responsive linker end-cap, we prepared amphiphilic block copolymers of PEtG and poly(ethylene oxide) (PEO) that self-assembled to form light-responsive nanoparticles. ${ }^{22}$ In 
addition, we recently reported end-caps responsive to $\mathrm{H}_{2} \mathrm{O}_{2}$, thiols, weak acids, and multiple stimuli. ${ }^{28}$ However, these PEtG homopolymers were not water-soluble and the depolymerization was studied only in 9:1 $\mathrm{CD}_{3} \mathrm{CN}: \mathrm{D}_{2} \mathrm{O}$. Here we describe the development of linker end-caps responsive to biologically relevant stimuli, and their application for the preparation of PEO-PEtG-PEO block copolymers. These block copolymers are self-assembled to form nanoparticles and the response of these nanoparticles to stimuli is studied. It is demonstrated that very low amounts of stimulus are sufficient to disrupt the assemblies. Furthermore, by simply changing the linker end-cap, these nanoparticles can be easily tuned to release drug molecules such as doxorubicin (Dox) and curcumin (Cur) using different stimuli such as light, thiols, and $\mathrm{H}_{2} \mathrm{O}_{2}$.

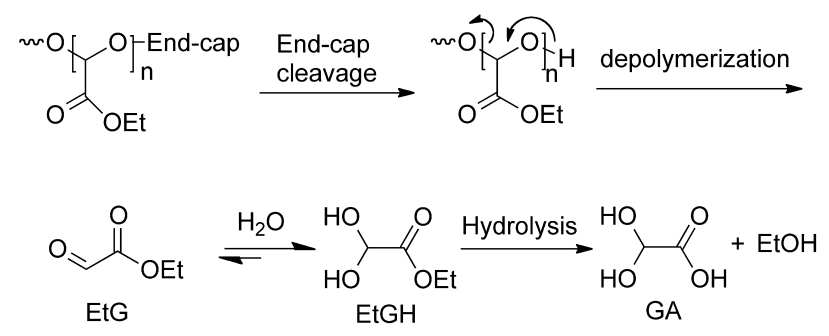

Figure 1. Depolymerization of PEtG to ethyl glyoxylate (EtG), hydration to form ethyl glyoxylate hydrate (EtGH), and hydrolysis to glyoxylic acid (GA) and ethanol.

\section{Experimental section}


General materials and procedures. Compounds $1,{ }^{28} 2,{ }^{22} \mathbf{5},{ }^{22} \mathbf{9},{ }^{28}$ azide-terminated PEO $\left(\right.$ PEO-N $\left._{3}\right),{ }^{38}$ thiol-terminated PEO (PEO-SH), ${ }^{39}$ and polymers PEtG-nitrobenzyl ${ }^{22}$,

PEtG-disulfide, ${ }^{28}$ and PEtG-nitrobenzyl-PEO ${ }^{22}$ were previously reported and the same batches were used. All other synthesis procedures are included in the supporting information. Ultrapure water was obtained from a Barnstead EASYpure II system. SEC was performed in THF at 1 $\mathrm{mL} / \mathrm{min}$ using a Viscotek GPC Max VE2001 solvent module equipped with a Viscotek VE3580 RI detector operating at $30^{\circ} \mathrm{C}$, two Agilent Polypore $(300 \times 7.5 \mathrm{~mm})$ columns, and a Polypore guard column $(50 \times 7.5 \mathrm{~mm})$. A calibration curve was obtained using poly(methyl methacrylate) standards. Thermogravimetric analysis (TGA) was performed on Q50 from TA Instruments with a heating rate of $10^{\circ} \mathrm{C} / \mathrm{min}$ from $35-800{ }^{\circ} \mathrm{C}$ under nitrogen. Spectra/Por regenerated cellulose membranes were used for dialyses. Dynamic light scattering (DLS) was performed using a Zetasizer Nano ZS instrument from Malvern Instruments at $25{ }^{\circ} \mathrm{C}$ at a concentration of 0.8 $\mathrm{mg} / \mathrm{mL}$ of polymer assemblies. TEM imaging was done using a Phillips CM10 microscope operating at an acceleration voltage of $80 \mathrm{kV} .3 \mu \mathrm{L}$ of micelle suspension $(0.3 \mathrm{mg} / \mathrm{mL})$ was placed onto a copper grid. The resulting sample was air-dried for $24 \mathrm{~h}$ before imaging. At least 30 particles were measured to obtain the mean particle diameters. Fluorescence spectra were obtained using a QM-4 SE spectrometer from Photon Technology International (PTI) equipped with double excitation and emission monochromators. UV-visible spectra were obtained on a Varian UV/VIS Cary 300 spectrophotometer. 
Nanoparticle preparation. $8 \mathrm{mg}$ of block copolymer was dissolved in $1.0 \mathrm{~mL}$ of DMSO with stirring overnight. $0.1 \mathrm{~mL}$ of the solution was injected quickly into $0.9 \mathrm{~mL}$ of rapidly stirring deionized water. After stirring for $0.5 \mathrm{~h}$, the suspension was dialyzed using a $3 \mathrm{~kg} / \mathrm{mol}$ molecular weight cut-off (MWCO) membrane against deionized water $(1 \mathrm{~L}, 24 \mathrm{~h}$, water changed once at $\sim 12 \mathrm{~h}$ ) to remove DMSO. Each nanoparticle system was prepared in triplicate.

Nanoparticle degradation studied by DLS. Nanoparticles were prepared as above, except that the suspensions were dialyzed against either $100 \mathrm{mM}, \mathrm{pH} 7.4$ phosphate buffer or $100 \mathrm{mM}, \mathrm{pH}$ 5.0 citrate buffer $(1 \mathrm{~L}, 24 \mathrm{~h}$, water changed once at $\sim 12 \mathrm{~h}$ ). The polymer concentration was $\sim 0.8$ $\mathrm{mg} / \mathrm{mL}$. The count rate was measured by DLS while fixing the attenuator at 7. DTT or $\mathrm{H}_{2} \mathrm{O}_{2}$ were added at concentrations ranging from $0.05-10 \mathrm{mM}$ or not added in the case of controls. Irradiation with UV light was performed in an ACE Glass photochemistry cabinet containing a mercury light source ( $450 \mathrm{~W}$ bulb, $2.8 \mathrm{~mW} / \mathrm{cm}^{2}$ of UVA radiation) for $20 \mathrm{~min}$. After applying the stimuli, the samples were incubated at $37^{\circ} \mathrm{C}$ in the dark and the DLS count rate was measured at selected time points. PEtG-nitrobenzyl-PEO and PEtG-multi-PEO were studied in triplicate.

Nanoparticle depolymerization studied by NMR spectroscopy. $16 \mathrm{mg}$ of copolymer was dissolved in $0.8 \mathrm{~mL}$ of DMSO- $d_{6} .0 .2 \mathrm{~mL}$ of the resulting solution was rapidly injected into 1.0 $\mathrm{mL}$ of $100 \mathrm{mM}$, pH 7.4 phosphate- or $100 \mathrm{mM}$, pH 5.0 citrate-buffered $\mathrm{D}_{2} \mathrm{O}$. After stirring for $0.5 \mathrm{~h}$, the nanoparticle suspension was transferred into NMR tubes, and initial ${ }^{1} \mathrm{H}$ NMR spectra 
were obtained. The corresponding stimuli were applied as described above for the DLS study. The samples were incubated at $37^{\circ} \mathrm{C}$ and NMR spectra were obtained at time points over 1 or 2 days. The integration of the PEO peak at $3.6 \mathrm{ppm}$ was set to 364 for the PEO $2000 \mathrm{~g} / \mathrm{mol}$ conjugates or 136 for the $750 \mathrm{~g} / \mathrm{mol}$ conjugate. The integration of the peaks at $1.0-1.2 \mathrm{ppm}$ corresponding to the $\mathrm{CH}_{3}$ group on released EtGH and its ethanol hydrolysis product was measured ( $\mathrm{I}_{\mathrm{CH} 3}$ aq $)$ and compared its value in $\mathrm{CDCl}_{3}\left(\mathrm{I}_{\mathrm{CH} 3 \mathrm{CDCl}}\right.$ ) (it corresponds to the $\mathrm{CH}_{3}$ of the ethyl group on PEtG in this case) where both blocks are fully soluble, with the integration of the PEO peak set to 364 or 136 . The extent of depolymerization is determined as follows: \% depolymerization $=\left(\mathrm{I}_{\mathrm{CH} 3 \text { aq }} / \mathrm{I}_{\mathrm{CH} 3 \mathrm{CDCl} 13}\right) \times 100 \%$.

Loading and release of nile red. Nanoparticles were prepared as described above in $100 \mathrm{mM}$, pH 7.4 phosphate buffer or $100 \mathrm{mM}$, pH 5.0 citrate buffer $(1 \mathrm{~L}, 24 \mathrm{~h}$, water changed once at $\sim 12$ h) at $0.8 \mathrm{mg} / \mathrm{mL}$ of polymer. $29 \mu \mathrm{L}$ of a $0.1 \mathrm{mg} / \mathrm{mL}$ solution of nile red in $\mathrm{CH}_{2} \mathrm{Cl}_{2}$ was added to each of a series of vials and then the solvent was evaporated to provide a thin film of nile red. To each vial, $1.5 \mathrm{~mL}$ of nanoparticle suspension was added, and the vials were gently shaken for 16 $\mathrm{h}$ to incorporate nile red into the nanoparticles. Using an excitation wavelength of $540 \mathrm{~nm}$, the initial emission intensity of nile red was measured at $600 \mathrm{~nm}$. Stimuli were then applied as described above for the DLS study and the samples were incubated at $37^{\circ} \mathrm{C}$ in the dark. The emission intensity at $600 \mathrm{~nm}$ was measured at selected time points. 
Loading and release of Dox. $10 \mathrm{mg}$ of Dox $(17.2 \mu \mathrm{mol})$ and $1.74 \mathrm{mg}$ of triethylamine (17.2 $\mu \mathrm{mol}$ ) were dissolved in $2 \mathrm{~mL}$ DMSO and stirred for $10 \mathrm{~min}$, then $16 \mathrm{mg}$ of PEtG-nitrobenzyl-PEO was added and the solution was stirred for $5 \mathrm{~h}$. It was then injected quickly into $18 \mathrm{~mL}$ of deionized water and stirred for $15 \mathrm{~min}$. The suspension was dialyzed against water ( $1 \mathrm{~L}, 48 \mathrm{~h}$, water changed every $\sim 12 \mathrm{~h}$ ) using a $3500 \mathrm{~g} / \mathrm{mol}$ MWCO membrane to remove free Dox and DMSO. To calculate the Dox content and loading efficiency, a portion of the suspension was lyophilized, then a measured mass of the product was dissolved in DMF. The absorbance of the DMF solution was measured by UV-vis spectroscopy at $500 \mathrm{~nm}$ and the Dox concentration was calculated based on a Dox calibration curve $(\varepsilon=46820 \mathrm{~L} / \mathrm{g} \cdot \mathrm{cm})$. Loading efficiency $=($ mass of loaded drug $/$ mass of actual drug used $) \times 100 \%$. Drug content $=($ mass of loaded drug/mass of nanoparticles with drug) $\times 100 \%$. Dox release was measured in $100 \mathrm{mM}, \mathrm{pH}$ 5.0 citrate or $100 \mathrm{mM}, \mathrm{pH} 7.4$ phosphate buffer at polymer concentrations of 0.8 and $0.2 \mathrm{mg} / \mathrm{mL}$ respectively. $5 \mathrm{~mL}$ sample was irradiated with UV light as described above but for $3 \mathrm{~h}$, while another $5 \mathrm{~mL}$ was kept in the dark. At each $\mathrm{pH}$, the initial absorption was measured at $500 \mathrm{~nm}$. Each sample was then transferred into a dialysis membrane (3500 g/mol MWCO) and dialyzed in the dark against the corresponding buffer solutions ( $1 \mathrm{~L}, 48 \mathrm{~h}$, water changed every $\sim 12 \mathrm{~h}$ ) at $37^{\circ} \mathrm{C}$. The absorbance of the samples inside the dialysis membrane were measured at selected times over 2 or 4 days to quantify the percentage of released drug. 
Loading and release of Cur. 10 mg of PEtG-boronate-PEO, PEtG-disulfide-PEO, or PEtG-nitrobenzyl-PEO (control) and $2 \mathrm{mg}$ of Cur were dissolved in $1 \mathrm{~mL} \mathrm{DMF}$ and stirred overnight. The solution was then injected into $9 \mathrm{~mL}$ of stirring deionized water and stirred for an additional $1 \mathrm{~min}$. The suspension was then dialyzed against $100 \mathrm{mM}, \mathrm{pH} 7.4$ phosphate buffer (1 $\mathrm{L}, 16 \mathrm{~h}$, buffer changed at $\sim 8 \mathrm{~h}$ ) using a $3500 \mathrm{~g} / \mathrm{mol}$ MWCO membrane. It was then filtered through a $0.45 \mu \mathrm{m}$ syringe filter (Acrodisc Syringe Filter Non-Pyrogenic $13 \mathrm{~mm}$, Pall Life Science) to remove any unencapsulated and precipitated drug. The procedure for calculation of the drug content and loading efficiency is provided in the supporting information. To measure the drug release rates, $50 \mu \mathrm{L}$ of the resulting nanoparticle suspension was diluted into $2 \mathrm{~mL}$ of DMF to fully dissolve the copolymer and Cur and the absorbance at $428 \mathrm{~nm}$ was used to calculate the initial Cur concentration $(\varepsilon=5740 \mathrm{~L} / \mathrm{g} \cdot \mathrm{cm})$. The relevant stimuli $\left(\mathrm{H}_{2} \mathrm{O}_{2}\right.$ or DTT; 0.5 or $5 \mathrm{mM}$ ) were added (or not added for controls) to the resulting nanoparticles in buffer ( $5 \mathrm{~mL}$ per sample) and they were incubated in the dark at $37{ }^{\circ} \mathrm{C}$. At selected time points, $\sim 0.2 \mathrm{~mL}$ of the suspension was removed and filtered through a $0.45 \mu \mathrm{m}$ syringe filter to remove the released Cur. $50 \mu \mathrm{L}$ of the filtered suspension was then diluted into $2 \mathrm{~mL}$ of DMF, resulting in full dissolution. The absorbance of the DMF solution at $428 \mathrm{~nm}$ was measured to determine the percentage of drug remaining in the nanoparticles. 


\section{Results and Discussion}

\section{Synthesis of stimuli-responsive PEtG-PEO triblock copolymers}

In the current work, UV light, reducing conditions (i.e., thiols), $\mathrm{H}_{2} \mathrm{O}_{2}$ and combinations of these stimuli were targeted as triggers for initiating the depolymerization of PEO-PEtG-PEO

assemblies for the release of drugs. As described above, thiols and $\mathrm{H}_{2} \mathrm{O}_{2}$ are stimuli that are relevant to pathological conditions such as inflammation and cancer. ${ }^{40,41}$ Light is a stimulus that can be easily applied in the laboratory with good spatiotemporal control, and can potentially be extended to two-photon processes for application in vivo. ${ }^{42}$ Based on previous work, chloroformates can effectively end-cap $\mathrm{PEtG}^{22}$ so end-caps containing a chloroformate along with the stimuli-responsive group and a site for the conjugation of the PEO block were designed.

The structures of the linker end-caps employed in the current work are shown in Figure 2. We have previously reported end-caps $\mathbf{1}^{28}$ and $\mathbf{2}^{22}$. End-cap $\mathbf{1}$ contains a disulfide, which can serve both as a site for the conjugation of PEO via thiol exchange and as a reduction-sensitive site. Reaction with a thiol trigger releases a thiol on the end-cap that cyclizes, releasing uncapped PEtG (Scheme S1a). End-cap 2 contains an alkyne for conjugation of the PEO block using a $\mathrm{Cu}(\mathrm{I})$-assisted azide-alkyne cycloaddition (CuAAC) and a light-responsive $o$-nitrobenzyl moiety, that cleaves at the benzylic site to release uncapped PEtG (Scheme S1b). End-cap 3 contains an alkyne for $\mathrm{CuAAC}$ and a phenylboronate that is sensitive to $\mathrm{H}_{2} \mathrm{O}_{2}$. In the presence of $\mathrm{H}_{2} \mathrm{O}_{2}$, the boronate is cleaved. This releases the phenol, that undergoes a 1,6-elimination-decarboxylation, 
followed by a 1,4-elmination-decarboxylation to release uncapped PEtG (Scheme S1c). Finally, end-cap 4 contains an alkyne as well as both the boronate and $o$-nitrobenzyl groups, allowing it to release uncapped PEtG in response to either $\mathrm{H}_{2} \mathrm{O}_{2}$ or UV light by a series of elimination-decarboxylation reactions (Scheme S1d).

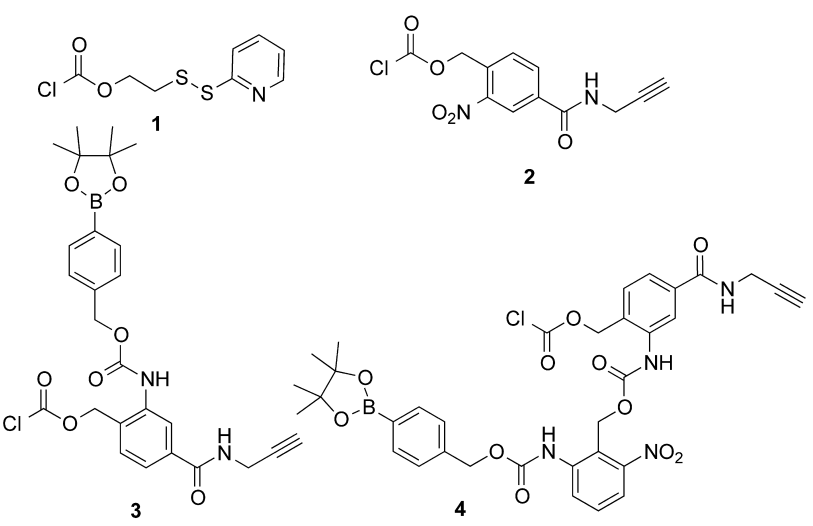

Figure 2. Chemical structures of linker end-caps each containing a chloroformate, one or more stimuli-responsive moieties, and a site for conjugation of PEO.

End-caps $\mathbf{1}^{28}$ and $\mathbf{2}^{22}$ were prepared as previously reported. The preparation of end-cap $\mathbf{3}$ began with reduction of the nitro group in the $o$-nitrobenzyl alcohol $5^{22}$ using $\mathrm{SnCl}_{2}$ to afford the aniline 6 (Scheme 1). Selective reaction of the chloroformate $7^{43}$ with the aniline group in 6 provided compound $\mathbf{8}$. Finally, activation with phosgene in THF/toluene provided end-cap 3. Recently, we reported chloroformate 9 as an end-cap that was responsive to both UV light and $\mathrm{H}_{2} \mathrm{O}_{2}{ }^{28}{ }^{2}$ was reacted selectively with the aniline group in compound $\mathbf{6}$ to afford compound $\mathbf{1 0}$, which was then activated with phosgene to provide end-cap 4 (Scheme 2). 


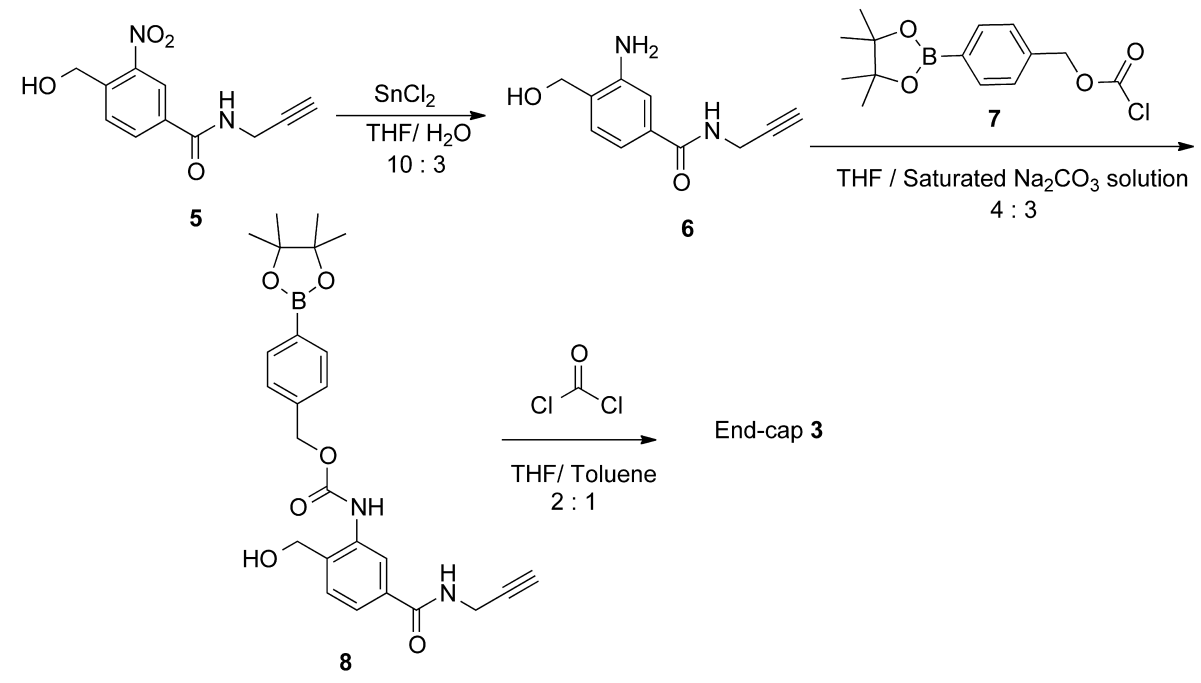

Scheme 1. Synthesis of end-cap 3.
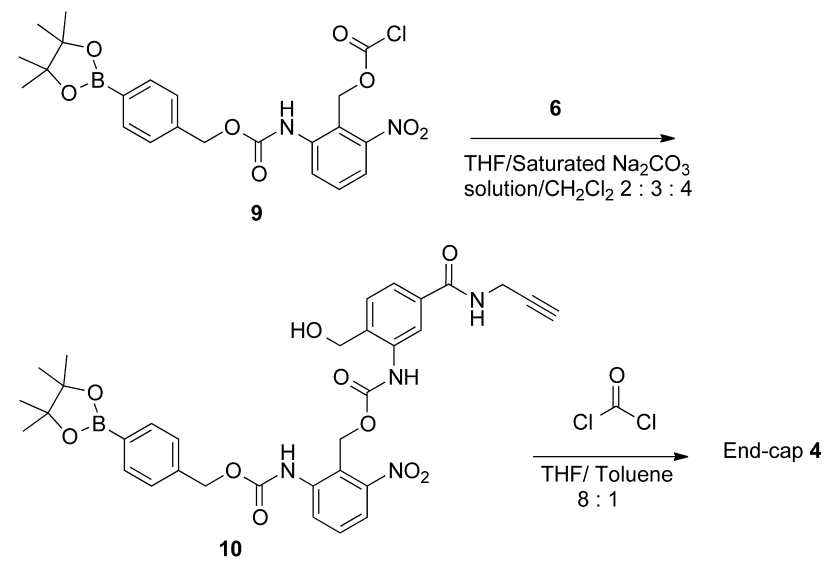

Scheme 2. Synthesis of end-cap 4.

Following the previously reported procedure, PEtG was synthesized by the polymerization of freshly distilled ethyl glyoxylate in $\mathrm{CH}_{2} \mathrm{Cl}_{2}$ at $-20{ }^{\circ} \mathrm{C}$ in the presence of catalytic $\mathrm{NEt}_{3}$ (Scheme 3). ${ }^{22}$ End-cap and additional $\mathrm{NEt}_{3}$ were then added at $-20^{\circ} \mathrm{C}$ to end-cap the polymer and then the reaction was gradually warmed to room temperature. Capping with compounds $\mathbf{1 , 2 , 3}$, and $\mathbf{4}$, provided PEtG-disulfide, ${ }^{28}$ PEtG-nitrobenzyl, ${ }^{22}$ PEtG-boronate, and PEtG-multi respectively. The polymers have end-caps at each terminus because EtGH generated from trace 
$\mathrm{H}_{2} \mathrm{O}$ still present in the monomer after distillation initiates the polymerization. The PEtGs were purified by precipitation in methanol, except for PEtG-multi, which did not precipitate in methanol and was instead purified by dialysis.

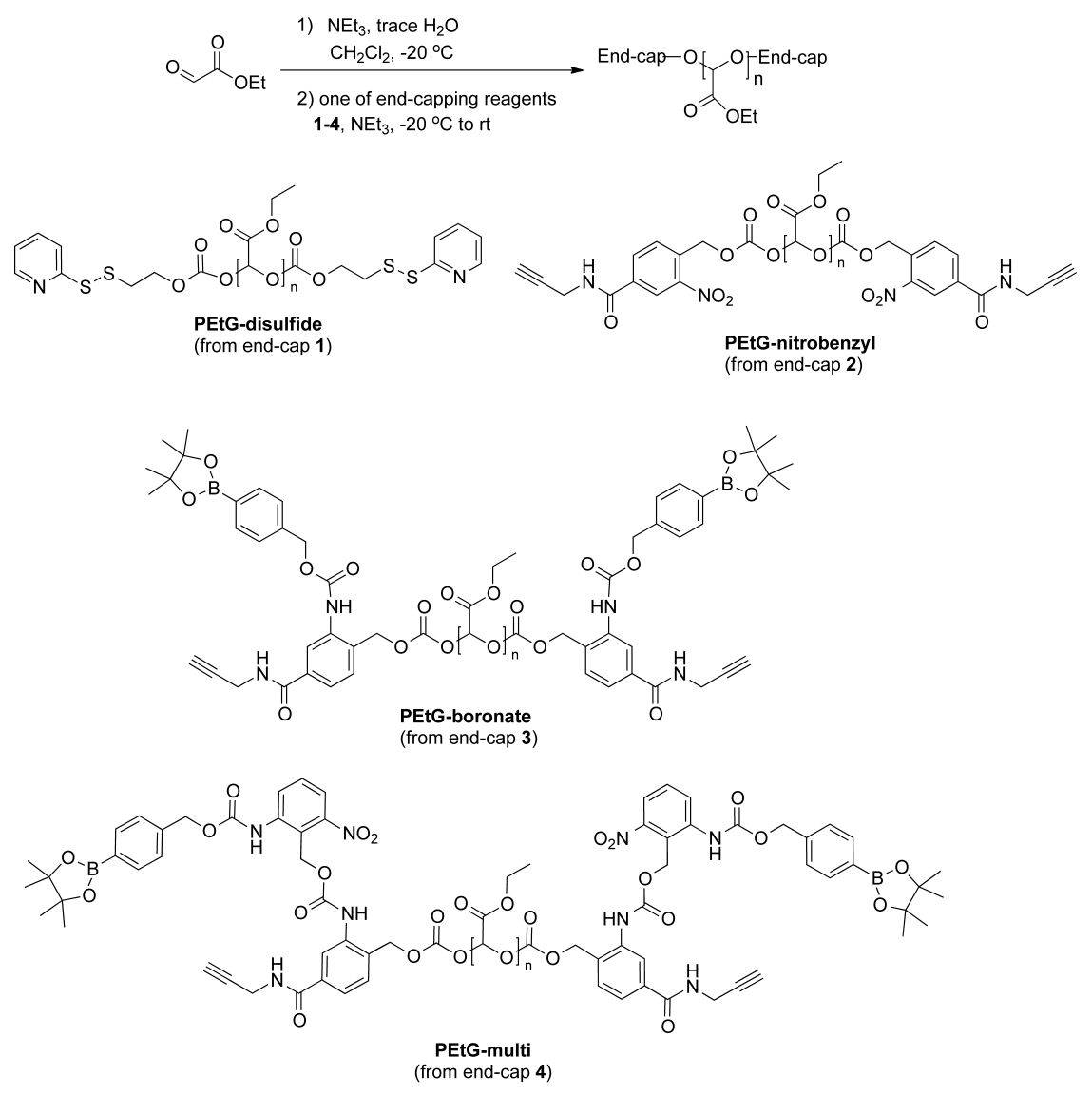

Scheme 3. Synthesis of end-capped PEtGs.

The polymers were characterized by ${ }^{1} \mathrm{H}$ NMR spectroscopy, SEC, and TGA. NMR spectra were consistent with the proposed structures, although it was difficult to detect the end-cap peaks due to the high degrees of polymerization. Based on SEC analysis relative to PMMA standards, the molar masses of PEtG-disulfide, PEtG-nitrobenzyl, and PEtG-boronate ranged from 26-48 kg/mol and the dispersities $(Ð)$ ranged from 1.4-2.1 (Table 1). PEtG-multi had a 
somewhat lower $\mathrm{M}_{\mathrm{n}}$ of $6.3 \mathrm{~kg} / \mathrm{mol}$, likely due to the poor solubility of end-cap $\mathbf{4}$ as well as high steric hindrance. It is possible that some depolymerization occurred before complete end-capping could be achieved. TGA showed that all of the polymers were quite thermally stable with onset degradation temperatures $\left(\mathrm{T}_{\mathrm{o}}\right)$ greater than $160^{\circ} \mathrm{C}$. This confirmed complete end-capping of the isolated polymers as uncapped PEtG is thermally unstable and begins depolymerizing almost immediately upon heating. ${ }^{22}$

Table 1. Properties of PEtG with different linker end-caps and PEO-PEtG-PEO copolymers.

${ }^{a}$ These polymers have been previously reported. ${ }^{22}$

\begin{tabular}{|c|c|c|c|}
\hline Polymer & $\begin{array}{c}\mathrm{M}_{\mathrm{n}}(\mathrm{SEC}) \\
(\mathrm{kg} / \mathrm{mol})\end{array}$ & $\theta$ & $\begin{array}{r}\mathrm{T}_{\mathrm{o}} \\
\left({ }^{\circ} \mathrm{C}\right)\end{array}$ \\
\hline PEtG-disulfide ${ }^{a}$ & 26 & 1.4 & 191 \\
\hline PEtG-nitrobenzyl ${ }^{a}$ & 42 & 2.1 & - \\
\hline PEtG-boronate & 48 & 1.5 & 165 \\
\hline PEtG-multi & 6.3 & 1.6 & 204 \\
\hline PEtG-disulfide-PEO & 29 & 1.4 & 179 \\
\hline PEtG-nitrobenzyl-PEO $^{a}$ & 40 & 2.1 & 203 \\
\hline PEtG-boronate-PEO & 49 & 1.7 & 181 \\
\hline PEtG-multi-PEO & 7.7 & 1.5 & 164 \\
\hline
\end{tabular}


The next step was the conjugation of PEO to the reactive functional groups on the end-caps. PEO was selected as the hydrophilic block because it can be easily functionalized at its terminus and provides good water-dispersibility and biocompatibility in drug delivery applications. ${ }^{44,45}$ In previous work, small spherical nanoparticles were formed from a PEO-PEtG-PEO triblock copolymer with a hydrophilic mass fraction $(f)$ of 0.10 , where $f=$ mass of $\mathrm{PEO} /($ mass of $\mathrm{PEO}+$ mass of PEtG). ${ }^{22}$ Therefore, similar $f$ values were targeted for the current work. While vesicles or larger particles would often be expected at such a low $f$ values, ${ }^{1,46}$ this was attributed to the hydrophilicity of PEtG in comparison with other common hydrophobic blocks such as polybutadiene and polycaprolactone. PEtG-disulfide was coupled with PEO-SH via a disulfide exchange reaction in DMF to afford PEtG-disulfide-PEO (Scheme 4). PEtG-nitrobenzyl and PEtG-boronate were coupled to $2000 \mathrm{~g} / \mathrm{mol} \mathrm{PEO}^{-\mathrm{N}_{3}}$ by CuAAC in DMF to afford PEtG-nitrobenzyl-PEO and PEtG-boronate-PEO respectively. Because of its lower initial $\mathrm{M}_{\mathrm{n}}$, PEtG-multi was coupled with $750 \mathrm{~g} / \mathrm{mol} \mathrm{PEO} \mathrm{N}_{3}$ to provide PEtG-multi-PEO. In each case, the excess PEO was removed by dialysis and washing with water. 
a)

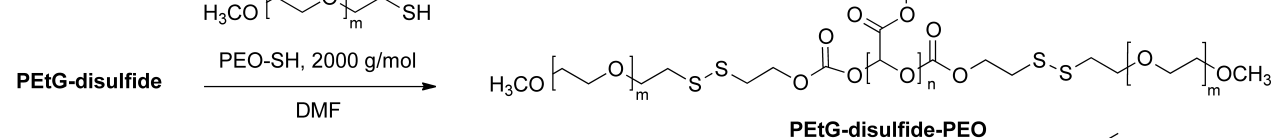

b)
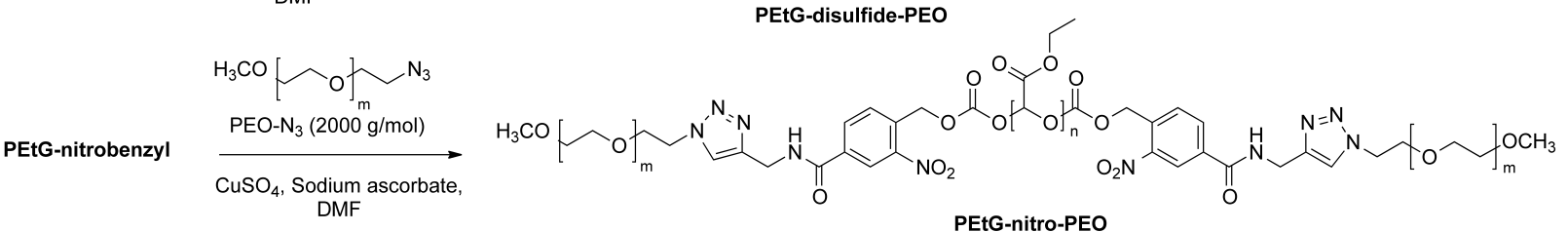

c)

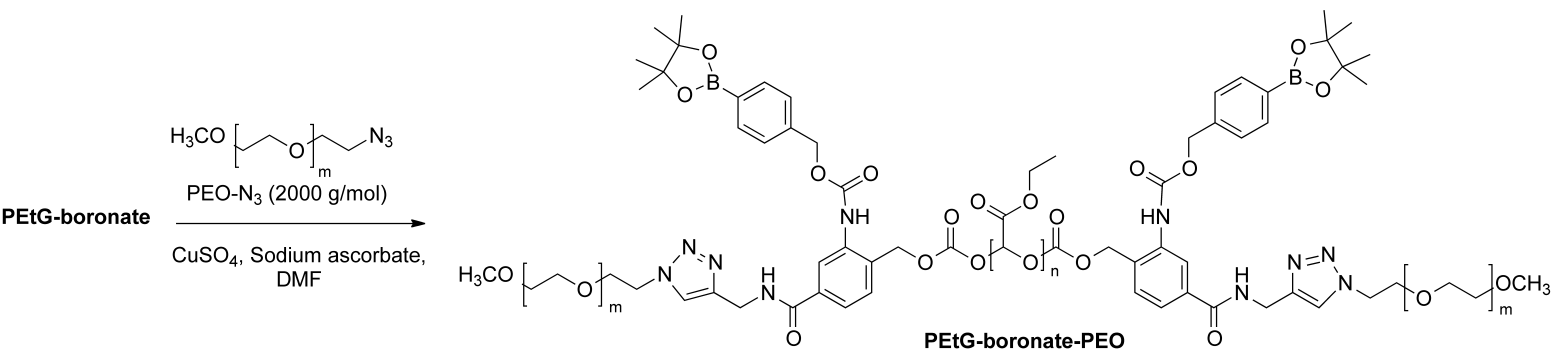

d)
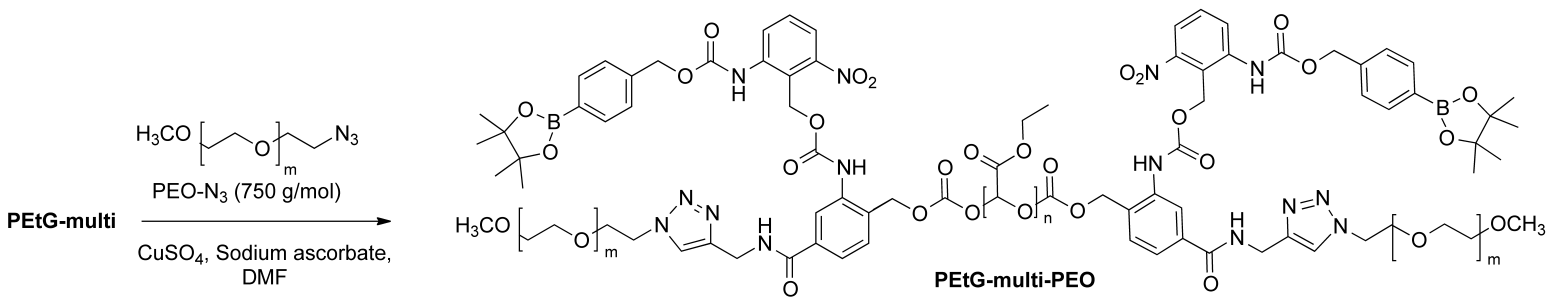

Scheme 4. Synthesis of PEO-PEtG-PEO copolymers a) PEtG-disulfide-PEO, b)

\section{PEtG-nitro-PEO, c) PEtG-boronate-PEO, and d) PEtG-multi-PEO.}

The purified block copolymers were characterized by ${ }^{1} \mathrm{H}$ NMR spectroscopy, SEC, and TGA.

Removal of uncoupled PEO was confirmed by SEC as no peaks corresponding to free PEO were observed (Figures S15-S17). Only small increases in the $\mathrm{M}_{\mathrm{n}} \mathrm{s}$ for the block copolymers relative to the starting PEtGs were observed and there were no significant changes in their $\oslash$ values. Based on the integrations of the PEO peak relative to those of the PEtG in the ${ }^{1} \mathrm{H}$ NMR spectra, the CuAAC provided full conversion of the terminal alkynes to triazoles (Figure S13-S14). The $f$ values for these polymers were calculated as 0.09 and 0.08 for PEtG-nitrobenzyl-PEO and 
PEtG-boronate-PEO respectively (Table 2). PEtG-multi-PEO had a higher $f$ value of 0.20 due to the much lower initial $\mathrm{M}_{\mathrm{n}}$ of the PEtG block. On the other hand, the disulfide exchange reaction resulted in only $\sim 50 \%$ conversion of the dithiopyridyl groups (Figure S12). This was deemed sufficient for nanoparticle formation as PEtG-disulfide-PEO had an $f$ value of 0.08 , very similar to that of the other copolymers. The $T_{0}$ values for the block copolymers were similar to those of PEtG, although a 2-step degradation process was observed, with the first phase corresponding to PEtG and the second corresponding to PEO (Figures S19).

Table 2. Hydrophilic mass fractions $(f)$ of the block copolymers and corresponding characterization of self-assembled nanoparticles by DLS and CAC measurement. Errors on the measurements correspond to the standard deviations.

\begin{tabular}{|c|c|c|c|c|c|}
\hline Copolymer & $f$ & Mean diameter & Z-average & PDI & CAC \\
& measured by & diameter (nm) & & $(\mu \mathrm{g} / \mathrm{mL})$ \\
\hline PEM (nm) & & $83 \pm 1$ & $0.19 \pm 0.02$ & 40 \\
\hline PEtG-nitrobenzyl-PEO & 0.10 & $53 \pm 17$ & $82 \pm 2$ & $0.17 \pm 0.03$ & 32 \\
\hline PEtG-boronate-PEO & 0.08 & $64 \pm 26$ & $85 \pm 11$ & $0.22 \pm 0.05$ & 32 \\
\hline PEtG-multi-PEO & 0.20 & $47 \pm 7$ & $47 \pm 9$ & $0.18 \pm 0.05$ & 25 \\
\hline
\end{tabular}




\section{Self-assembly of PEtG-PEO triblock copolymers in aqueous solution}

Self-assembly of each triblock copolymer was achieved by dissolving the polymer in DMSO and then injecting this solution into rapidly stirring water. The DMSO was then removed by dialysis. The hydrodynamic diameters and polydispersity indices (PDIs) of the resulting nanoparticles were measured by DLS (Figures S20-S23). The Z-average diameters of the nanoparticles ranged from $47 \mathrm{~nm}$ to $83 \mathrm{~nm}$ (Table 2). PEtG-multi-PEO formed the smallest assemblies, likely due to its relatively short block lengths and higher $f$ value, while all other assemblies were of similar size. The PDIs ranged from 0.17 to 0.22 , suggesting that the nanoparticles had reasonably narrow size distributions. TEM confirmed that the assemblies were solid, spherical particles (Figure 3). The mean diameters measured from the TEM images were smaller than those measured by DLS

(Table 2). This can be attributed to the particles being in the dry rather than hydrated state. Furthermore, even a small fraction of larger particles can significantly influence the Z-average diameter in DLS, due to the size dependence of the scattered light intensity. The critical aggregation concentrations (CACs) of the block copolymers were determined through the incorporation of the fluorescent probe nile red. ${ }^{47}$ The CAC values were all similar, ranging from $25-40 \mu \mathrm{g} / \mathrm{mL}$. We also investigated the stabilities of the assemblies in mouse serum. Each system was stable for $24 \mathrm{~h}$, and only the PEtG-boronate-PEO nanoparticles underwent some degradation over $96 \mathrm{~h}$, with a $\sim 30 \%$ reduction in count rate measured by DLS (Figure S24). 

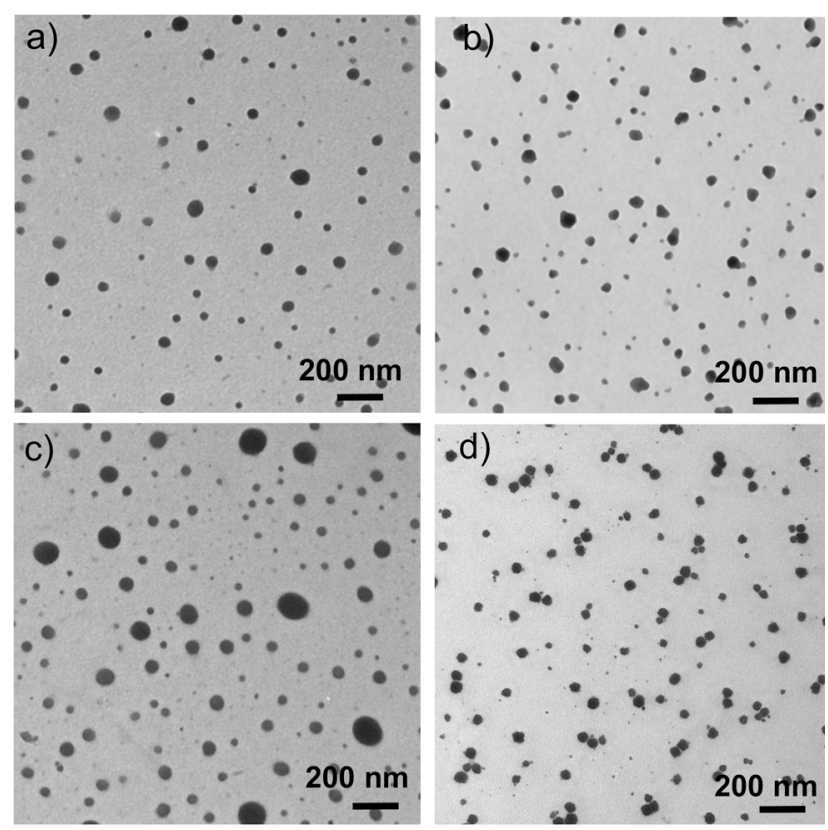

Figure 3. TEM images of nanoparticles formed from a) PEtG-disulfide-PEO, b)

PEtG-nitrobenzyl-PEO, c) PEtG-boronate-PEO, and d) PEtG-multi-PEO.

\section{Stimuli-responsive properties of the nanoparticles}

Depolymerization of the nanoparticles in response to stimuli was studied using DLS and NMR spectroscopy. For DLS, the nanoparticles were prepared as described above and were dialyzed into $100 \mathrm{mM}, \mathrm{pH} 7.4$ phosphate buffer unless otherwise indicated. After introduction of the stimulus, the nanoparticles were incubated at $37^{\circ} \mathrm{C}$. DLS can provide an indication of nanoparticle disintegration because the scattered light intensity, measured as the mean count rate, is proportional to the number of scattering species and their sizes. Disintegration of the micelles was expected to result in a decrease in the mean count rate. ${ }^{1} \mathrm{H}$ NMR spectroscopy was used to confirm that the disassembly of the nanoparticles was induced by the depolymerization of the 
PEtG block. For this experiment, the assemblies were prepared by injection of a DMSO- $d_{6}$ solution of the polymer into $\mathrm{pH} 7.4$ phosphate- or $\mathrm{pH} 5.0$ citrate-buffered $\mathrm{D}_{2} \mathrm{O}\left(\mathrm{D}_{2} \mathrm{O}:\right.$ DMSO- $d_{6}=$ 5:1). For practical reasons, the DMSO- $d_{6}$ was not removed. Prior to depolymerization, signals from the PEtG block were not observed in the NMR spectra because PEtG was packed into the nanoparticle core, resulting in very long relaxation times. However, upon depolymerization, peaks corresponding to the depolymerization product EtGH were observed and the percent depolymerization was measured based on the integration of peaks corresponding to this product relative to that of PEO.

The depolymerization of PEtG-disulfide-PEO nanoparticles was studied in the presence of varying concentrations of DTT, a commonly used thiol-based reducing agent. A reduction in count rate to less than $5 \%$ its initial value was observed in $3 \mathrm{~h}$ at $10 \mathrm{mM}$ DTT (Figure $4 \mathrm{a}$ ). The particle diameter remained constant over the first hour, then became multimodal and difficult to measure as the count rate became very low (Figure S25). The concentration of the thiol-based reducing agent glutathione has been reported to be as high as $15 \mathrm{mM}$ in cancer cells ${ }^{48}$ so the nanoparticles exhibit responsive behavior at physiologically-relevant reducing agent concentrations. This is particularly significant because when depolymerization of the homopolymer PEtG-disulfide was studied in 9:1 $\mathrm{CD}_{3} \mathrm{CN}: \mathrm{H}_{2} \mathrm{O}, 100 \mathrm{mM}$ DTT was required because much of the DTT was trapped by reaction with ethyl glyoxylate. ${ }^{28}$ The current results show that this trapping occurs to much less extent in the fully aqueous system where water 
competes more effectively as a nucleophile. However, it must also be noted that DTT is a stronger reducing agent than glutathione, so higher concentrations of glutathione would be required to achieve the same results as for DTT. ${ }^{49}$ Below $10 \mathrm{mM}$ DTT, the rate of nanoparticle degradation depended on the DTT concentration. At $1 \mathrm{mM}$ DTT and below, the diameter did not change significantly as the count rate decreased over $48 \mathrm{~h}$, suggesting that some assemblies were still present (Figure S25). In the absence of DTT, the particles were stable for $\sim 30 \mathrm{~h}$, after which some degradation occurred, likely as a result of hydrolysis of the carbonate on the end-cap. As an additional control, PEtG-nitro-PEO nanoparticles, that were not designed to respond to DTT, were also exposed to $10 \mathrm{mM}$ DTT. This system was stable for the first $10 \mathrm{~h}$, after which slow degradation occurred. This degradation can arise from the cleavage of the carbonate connecting the end-cap, which may be assisted by nucleophilic DTT. However, the effect of $10 \mathrm{mM}$ DTT on PEtG-nitro-PEO nanoparticles was clearly much less than on PEtG-disulfide-PEO nanoparticles. When the depolymerization was monitored by NMR spectroscopy at a concentration of $10 \mathrm{mM}$ DTT, the rate was found to be similar to that observed by DLS (Figure 4b) and the depolymerization product was a mixture of EtGH and the DTT adduct that was characterized in our previous work ${ }^{28}$ (Figure 4c). 

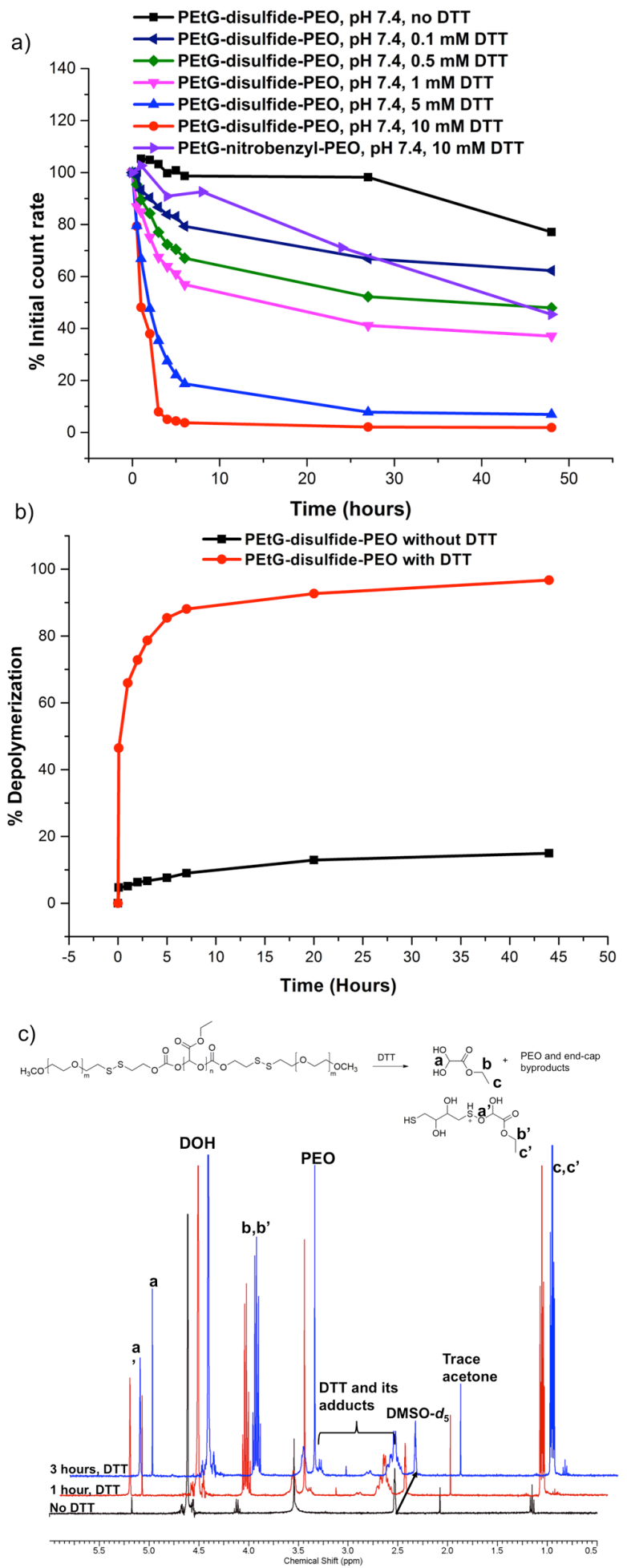
Figure 4. Stimuli-responsive properties of PEtG-disulfide-PEO nanoparticles: a) \% Initial count rate versus time (measured by DLS) for nanoparticles exposed to varying concentrations of DTT, b) \% Depolymerization versus time for PEtG-disulfide-PEO nanoparticles in 5:1 pH 7.4, phosphate buffered $\mathrm{D}_{2} \mathrm{O}$ :DMSO- $d_{6}$ in the absence and presence of $10 \mathrm{mM}$ DTT (measured by NMR spectroscopy). c) ${ }^{1} \mathrm{H}$ NMR spectra (400 MHz) of PEtG-disulfide-PEO nanoparticles in the same solvent. Peaks corresponding to the depolymerization products EtGH and the DTT adduct appear after the addition of $10 \mathrm{mM}$ DTT.

We have previously studied the depolymerization of PEtG-nitrobenzyl-PEO nanoparticles at $\mathrm{pH} 7.4$ by NMR spectroscopy, but we probed this in further detail here by DLS and also studied the depolymerization at $\mathrm{pH} 5.0$ (100 $\mathrm{mM}$ citrate buffer). To cleave the nitrobenzyl linker end-cap, samples were irradiated with $2.8 \mathrm{~mW} / \mathrm{cm}^{2}$ of UVA light for $20 \mathrm{~min}$. As shown in Figure 5a, after UV irradiation and incubation at $37^{\circ} \mathrm{C}$, a rapid decrease in the count rate was observed to less than $10 \%$ the initial value within $1 \mathrm{~h}$ at $\mathrm{pH}$ 7.4. The decrease was slower at $\mathrm{pH} 5.0$, requiring $6 \mathrm{~h}$ to reach $\sim 20 \%$ the initial value. This $\mathrm{pH}$ dependence arises because depolymerization occurs via hemiacetal breakdown, which can be catalyzed by acid or base, and exhibits a rate minimum at mildly acidic $\mathrm{pH} .{ }^{50}$ When PEtG-nitrobenzyl-PEO nanoparticles were not irradiated, there was no significant change in the count rate over $6 \mathrm{~h}$. As an additional control experiment, non-light-sensitive PEtG-disulfide-PEO assemblies were also irradiated. 
No significant perturbations in count rate were observed. NMR spectroscopy in 5:1

$\mathrm{D}_{2} \mathrm{O}:$ DMSO- $d_{6}$ showed that depolymerization of PEtG-nitrobenzyl-PEO to EtGH occurred

following irradiation at a rate similar to that suggested by DLS (Figure S27). It also confirmed

that the depolymerization was faster at $\mathrm{pH} 7.4$ and that depolymerization did not occur to any

significant extent without irradiation (Figures S27-S29). Overall, these results confirm that

PEtG-nitrobenzyl-PEO nanoparticles can be selectively degraded by UV light. 

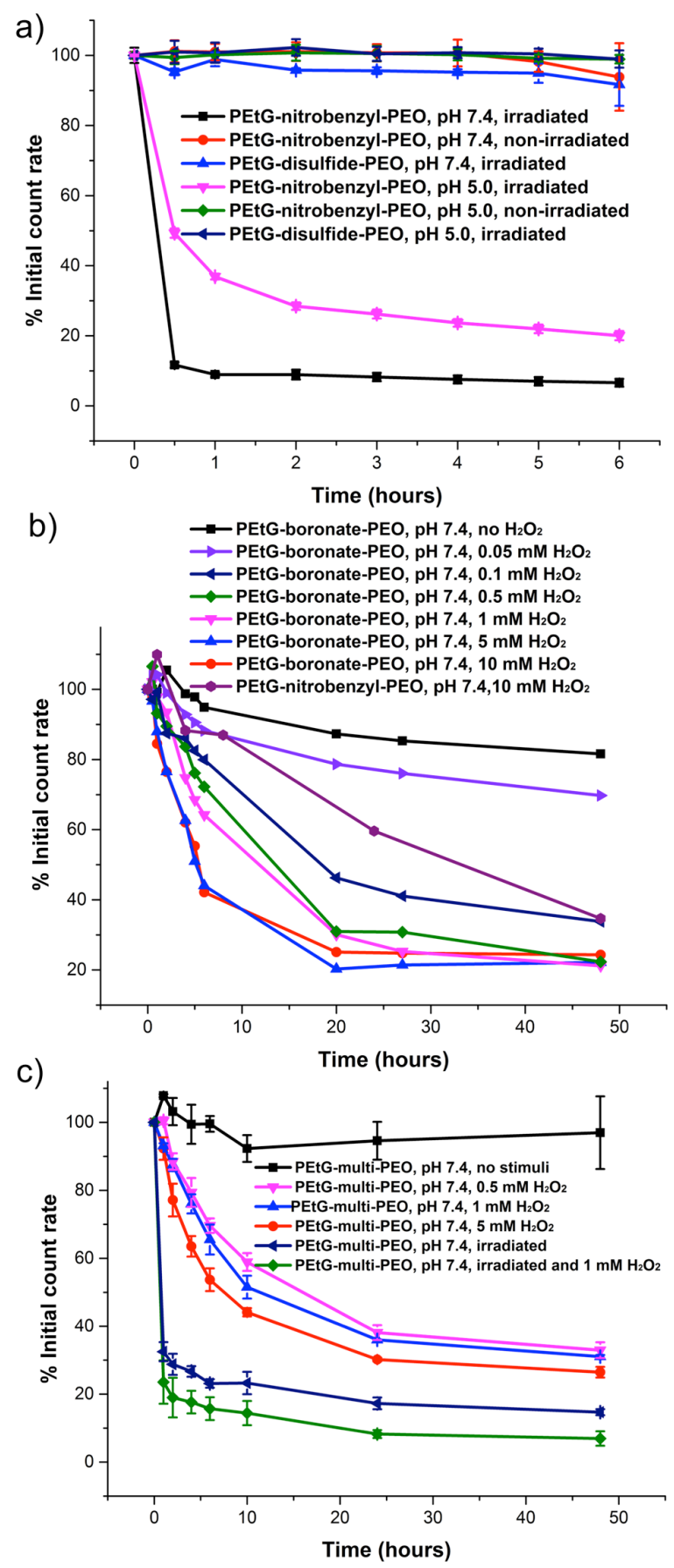

Figure 5. \% Initial count rate, measured by DLS, versus time for nanoparticles and their corresponding controls with or without stimuli: a) PEtG-nitrobenzyl-PEO nanoparticles with UV light, b) PEtG-boronate-PEO with $\mathrm{H}_{2} \mathrm{O}_{2}$, c) PEtG-multi-PEO with $\mathrm{H}_{2} \mathrm{O}_{2}$, UV light, or 
both. The study was carried out at $\mathrm{pH}$ 7.4, except for a) which was also performed at $\mathrm{pH}$ 5.0. The temperature was $37^{\circ} \mathrm{C}$. Error bars in a) and c) represent the standard deviation on 3 samples.

PEtG-boronate-PEO nanoparticles were studied in the presence of varying concentrations of $\mathrm{H}_{2} \mathrm{O}_{2}$. As shown in Figure $5 \mathrm{~b}$, even $0.05 \mathrm{mM} \mathrm{H}_{2} \mathrm{O}_{2}$ was able to induce an effect on the nanoparticles with a reduction in the count rate to $\sim 70 \%$ its initial value over $48 \mathrm{~h}$. This corresponds to less than 2 molar equiv. relative to the end-cap and less than 0.01 equiv. relative to monomer units in the polymer backbone. The ability of this system to respond to such low concentrations of $\mathrm{H}_{2} \mathrm{O}_{2}$ is a significant advance over previous work where a boronate-capped PEtG homopolymer in 9:1 $\mathrm{CD}_{3} \mathrm{CN}: \mathrm{D}_{2} \mathrm{O}$ required $\sim 100 \mathrm{mM} \mathrm{H}_{2} \mathrm{O}_{2}$ for complete depolymerization due to the trapping of nucleophilic $\mathrm{H}_{2} \mathrm{O}_{2}$ by EtG. ${ }^{28} \mathrm{H}_{2} \mathrm{O}_{2}$ is reported to be the most stable and highest concentration reactive oxygen species in living organisms, with concentrations varying significantly from $100 \mu \mathrm{M}$ to $0.01 \mu \mathrm{M}$, depending on the stage of cell growth. ${ }^{51,52}$ It can be present even in healthy cells, but the highest concentrations are usually associated with unhealthy states such as inflammation or cell apoptosis. In the current system, the rate of particle degradation continued to increase with increasing $\mathrm{H}_{2} \mathrm{O}_{2}$ concentration up to $\sim 5 \mathrm{mM} \mathrm{H}_{2} \mathrm{O}_{2}$. In the absence of $\mathrm{H}_{2} \mathrm{O}_{2}, 80 \%$ of the initial count rate was retained over $48 \mathrm{~h}$, with the small decrease likely resulting from non-specific cleavage as described above. As an additional control, the effect of $10 \mathrm{mM} \mathrm{H}_{2} \mathrm{O}_{2}$ on PEtG-nitro-PEO nanoparticles was investigated. Gradual degradation 
was observed for this control, suggesting that this concentration of nucleophilic $\mathrm{H}_{2} \mathrm{O}_{2}$ can induce some non-specific cleavage of the carbonate on the end-cap. However, the rate of degradation was still much slower than that resulting from the same concentration of $\mathrm{H}_{2} \mathrm{O}_{2}$ applied to PEtG-boronate-PEO nanoparticles. Study of the same system by NMR spectroscopy in 5:1 $\mathrm{D}_{2} \mathrm{O}: \mathrm{DMSO}-d_{6}$ with and without $10 \mathrm{mM} \mathrm{H}_{2} \mathrm{O}_{2}$ confirmed that PEtG-boronate-PEO nanoparticles depolymerized at similar rates to those observed by DLS and that the depolymerization product was EtGH (Figure S30).

Finally, the response of PEtG-multi-PEO to UV light, $\mathrm{H}_{2} \mathrm{O}_{2}$ and a combination of these stimuli was studied. As shown from Figure 5c, almost immediate degradation of the nanoparticles was observed after 20 min of UV irradiation. A slightly lower count rate was achieved using UV light and $\mathrm{H}_{2} \mathrm{O}_{2}$, which may result from the $\mathrm{H}_{2} \mathrm{O}_{2}$ being able to cleave a small amount of residual intact end-cap that remained after the irradiation. On the other hand, the degradation induced by $\mathrm{H}_{2} \mathrm{O}_{2}$ alone was significantly slower. As proposed in our previous work with PEtG homopolymers, this may arise from the requirement for multiple elimination reactions to initiate the depolymerization or from the trapping of reactive (azo)quinone methide species by depolymerizing PEtG. ${ }^{28}$ In the absence of stimuli, PEtG-multi-PEO nanoparticles were stable during $48 \mathrm{~h}$. NMR spectroscopy confirmed the depolymerization rate and that the expected products were produced (Figure S31-S32). 


\section{Encapsulation and triggered release of drugs and model drugs}

To demonstrate the encapsulation and release abilities of the nanoparticles, the hydrophobic dye nile red was first used as a model drug. It has strong fluorescence emission at $\sim 600 \mathrm{~nm}$ when it is in hydrophobic environments such as the cores of polymer nanoparticles, but its fluorescence is quenched in aqueous environments due to aggregation. ${ }^{53,54}$ This allows its release from nanoparticles to be probed. Nanoparticles were incubated with a thin film of nile red to load the dye into their cores then nile red release in response to stimuli was probed. As shown in Figure 6a, PEtG-disulfide-PEO released nile red at increasing rates with increasing concentrations of DTT in $\mathrm{pH} 7.4$ phosphate buffer at $37^{\circ} \mathrm{C}$. The rates were in general agreement with the DLS and NMR studies described above. $0.5 \mathrm{mM}$ DTT was the critical concentration required to provide a rapid release. Similar results were observed for PEtG-boronate-PEO nanoparticles, with 0.5 $\mathrm{mM} \mathrm{H}_{2} \mathrm{O}_{2}$ being the critical concentration to trigger the release of a substantial fraction of the nile red (Figure 6b).

Nile red-loaded PEtG-nitrobenzyl-PEO nanoparticles were triggered to release the dye by irradiation with UV light for $20 \mathrm{~min}$. The release of nile red at $\mathrm{pH} 7.4$ was very rapid, with the fluorescence decreasing to less than $20 \%$ its initial value in $20 \mathrm{~min}$ (Figure 6c). In agreement with the DLS and NMR studies, it was slightly slower at $\mathrm{pH} 5.0$, reaching less than $60 \%$ of the initial fluorescence in $20 \mathrm{~min}$. The photostability of nile red under the irradiation conditions was confirmed to ensure that the decrease in fluorescence was a result of its release from the particles 
and not from photodegradation (Figure S33). The rapid release of nile red from

PEtG-nitrobenzyl-PEO nanoparticles confirms that depolymerization is very rapid following end-cap cleavage and that the slower rates in some of the DTT and $\mathrm{H}_{2} \mathrm{O}_{2}$ conditions can likely be attributed to end-cap cleavage being the rate-determining step. 

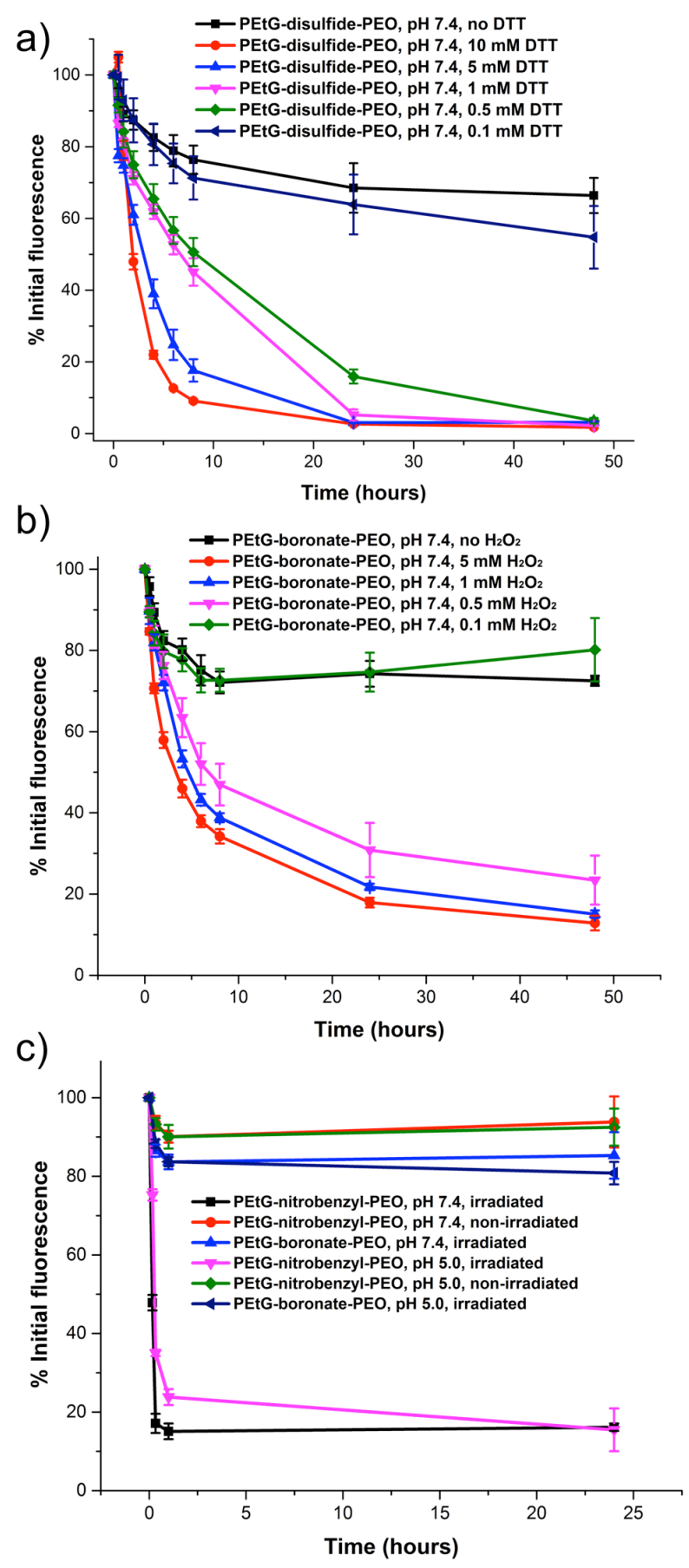

Figure 6. Change in nile red fluorescence intensity as an indicator of its release from nanoparticles composed of a) PEtG-disulfide-PEO, b) PEtG-boronate-PEO, and c) 
PEtG-nitrobenzyl-PEO in the presence and absence of their corresponding stimuli. Error bars correspond to the standard deviation on three samples.

The above results demonstrated that PEtG-based nanoparticles were capable of encapsulating and releasing cargo in response to their corresponding stimuli, so the next step was the loading and release of drug molecules. First, the encapsulation and release of Dox using PEtG-nitrobenzyl-PEO nanoparticles was investigated. Dox is a chemotherapeutic used in the treatment of a wide range of cancers. ${ }^{55}$ It was encapsulated during self-assembly by co-dissolving it with the polymer in DMSO prior to nanoparticle formation. Unencapsulated drug was removed by dialysis. The Dox content was $13 \mathrm{wt} \%$ and the loading efficiency was $\sim 23 \%$. The release of Dox from the nanoparticles with and without UV irradiation was monitored at $37^{\circ} \mathrm{C}$ at $\mathrm{pH} 7.4$ and 5.0 using dialysis to separate encapsulated and released drug. As shown in Figure 7, UV irradiation triggered a burst release $65 \%$ and $80 \%$ of the Dox at $\mathrm{pH}$ 7.4 and $\mathrm{pH} 5.0$ over the first $10 \mathrm{~h}$. The increased release at $\mathrm{pH}$ 5.0, which contrasts with that observed for nile red, can likely be attributed to increased protonation of Dox's primary amine group at $\mathrm{pH}$ 5. This increases its solubility in the aqueous medium outside the nanoparticle. In the absence of UV irradiation, the release was significantly slower at each $\mathrm{pH}$. 

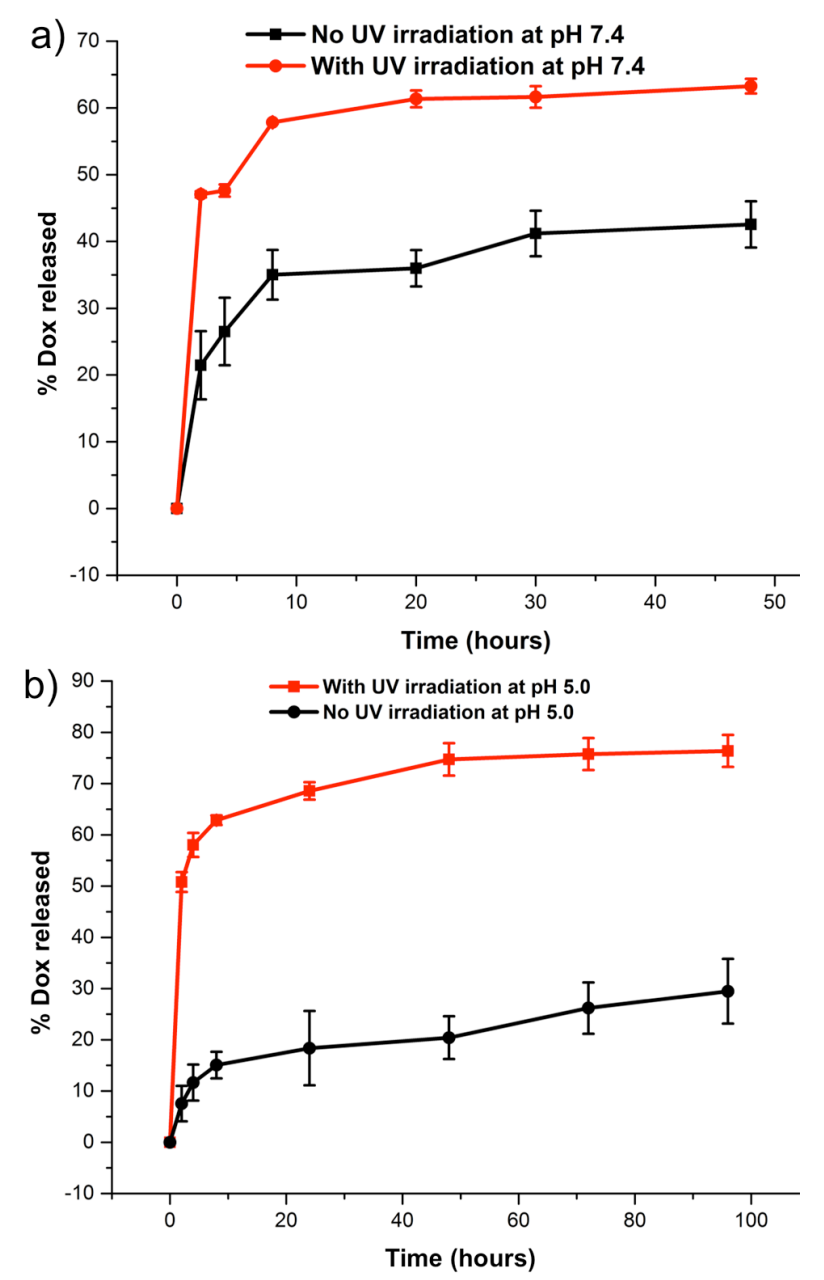

Figure 7. Release of Dox from PEtG-nitrobenzyl-PEO nanoparticles with and without UV irradiation at a) $\mathrm{pH} 7.4$ and b) $\mathrm{pH} 5.0$.

While the stimulus-triggered release was demonstrated with Dox, the relatively rapid background release in the absence of stimulus was not ideal, so additional drugs were investigated. Curcumin (Cur) is a naturally-occurring polyphenol that has been shown to inhibit cancer cell survival and proliferation. ${ }^{56}$ However, it suffers from poor solubility and bioavailability, so it would benefit significantly from an effective delivery system. As Cur is highly susceptible to photodegradation, PEtG-disulfide-PEO and PEtG-boronate-PEO were 
used with this drug, and PEtG-nitrobenzyl-PEO was used as a control system that should not be triggered by DTT or $\mathrm{H}_{2} \mathrm{O}_{2}$. Cur was encapsulated by dissolving it with the copolymer in DMF, then adding this solution to buffer to induce self-assembly. The free drug was removed by dialysis and insoluble particles were removed by filtration. This resulted in drug contents of 6.6 $\pm 0.3 \%, 8 \pm 2 \%$ and $11 \pm 2 \%$ and encapsulation efficiencies of $39 \pm 2 \%, 50 \pm 10 \%$ and $64 \pm$ $10 \%$ for PEtG-disulfide-PEO, PEtG-boronate-PEO and PEtG-nitrobenzyl-PEO respectively. In initial studies, it was observed that the rapid release of Cur in the presence of the stimuli resulted in fast precipitation of the drug. Therefore, the analysis of released drug by a dialysis-based method was not used. Instead, at each time point a small aliquot of the nanoparticle suspension was removed, filtered, and then a specified volume was diluted into DMF to provide complete dissolution. The absorbance of this solution at $428 \mathrm{~nm}$ was measured to determine the percentage of encapsulated curcumin that remained.

Both $0.5 \mathrm{mM}$ and $5 \mathrm{mM}$ DTT triggered the release of more than $95 \%$ of Cur from PEtG-disulfide-PEO nanoparticles in the first hour (Figure 8a). In contrast, in the absence of DTT $\sim 90 \%$ of the Cur was retained in the nanoparticles over $8 \mathrm{~h}$. The effect of DTT on Cur release from PEtG-nitrobenzyl-PEO nanoparticles was also investigated as a control. $90 \%$ of the drug was retained over $8 \mathrm{~h}$ in the presence of $0.5 \mathrm{mM}$ DTT. At $5 \mathrm{mM}$ DTT, the retention of curcumin in the nanoparticles dropped to $\sim 50 \%$ over $8 \mathrm{~h}$. This likely results from a direct reaction of DTT with Cur as thiols are known to undergo Michael addition reactions with Cur, 
disrupting $\pi$-conjugation and reducing its absorbance. ${ }^{57}$ However, the effect of DTT on

PEtG-disulfide-PEO nanoparticles at either concentration was still much greater than this background reaction, demonstrating the specificity of the triggering.
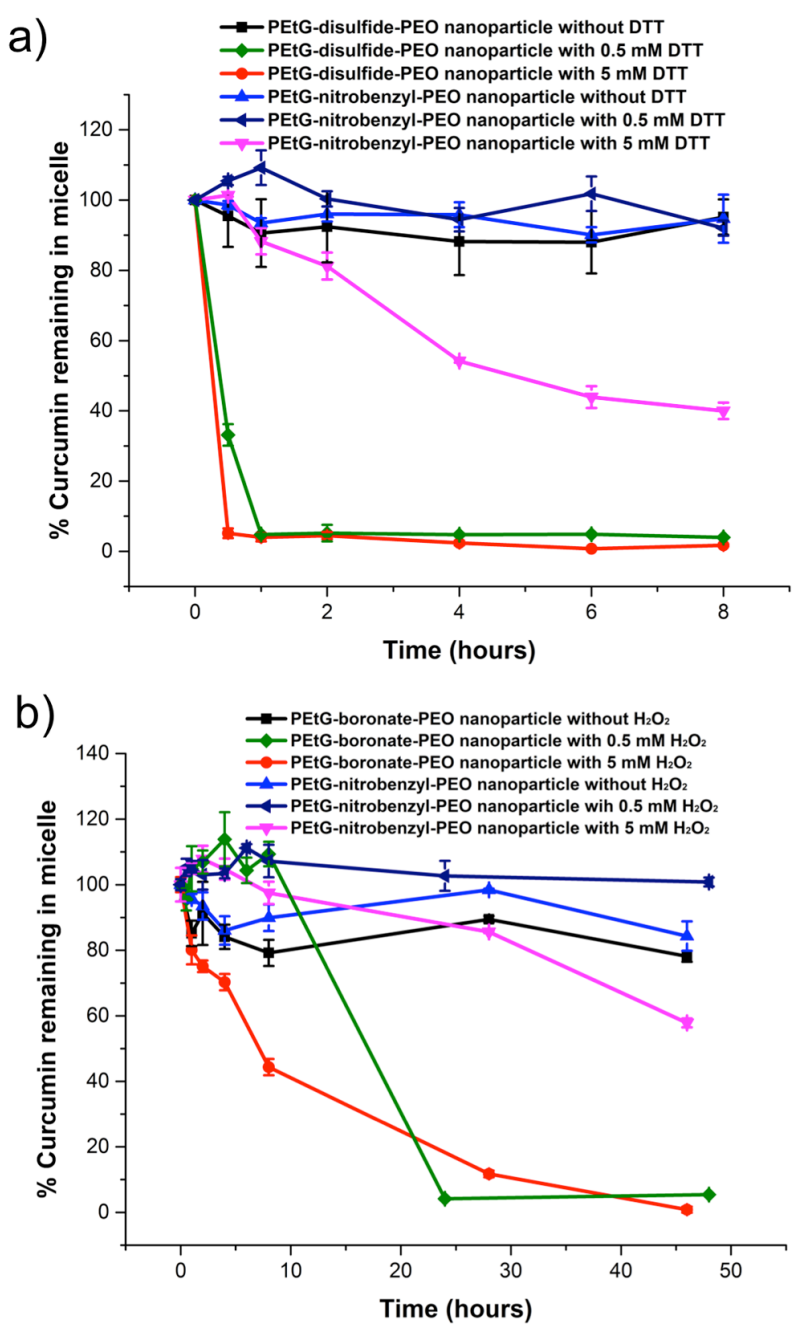

Figure 8. Curcumin retention in a) PEtG-disulfide-PEO and b) PEtG-boronate-PEO

nanoparticles in the presence and absence of stimuli as well as their corresponding controls. 
$\mathrm{H}_{2} \mathrm{O}_{2}$ triggered the release of Cur from PEtG-boronate-PEO micelles at concentrations of 0.5 or $5 \mathrm{mM}$. The release rate of Cur was faster at higher $\mathrm{H}_{2} \mathrm{O}_{2}$ concentrations due to faster cleavage of the end-cap. At $0.5 \mathrm{mM}$, a delay in the initiation of release for several hours was observed, suggesting that a critical amount of depolymerization is required to trigger the release. In the absence of $\mathrm{H}_{2} \mathrm{O}_{2}, \sim 80 \%$ of the Cur was retained in the PEtG-boronate-PEO nanoparticles over $48 \mathrm{~h}$. The response of Cur-loaded PEtG-nitrobenzyl-PEO nanoparticles to $\mathrm{H}_{2} \mathrm{O}_{2}$ was also investigated as a control experiment. As for DTT, it was found that $0.5 \mathrm{mM} \mathrm{H}_{2} \mathrm{O}_{2}$ did not result in any significant change in the encapsulated Cur. However, $5 \mathrm{mM} \mathrm{H}_{2} \mathrm{O}_{2}$ resulted in a slow decrease, reaching $\sim 60 \%$ the initial value after $48 \mathrm{~h}$. This could arise from the non-specific action of $\mathrm{H}_{2} \mathrm{O}_{2}$ on the PEtG-nitrobenzyl-PEO nanoparticles, as was observed in the DLS study. It could also arise from the reaction of Cur with $\mathrm{H}_{2} \mathrm{O}_{2}$ as Cur is well known to exhibit antioxidant activity by scavenging reactive oxygen species ${ }^{57}$ Nevertheless, there was again a large difference between the specific triggering of PEtG-boronate-PEO nanoparticles compared to the background reaction of PEtG-nitrobenzyl-PEO nanoparticles.

\section{Conclusions}

In conclusion, two previously developed and two new linker end-caps were used to prepare a series of amphiphilic PEO-PEtG-PEO copolymers responsive to thiols, $\mathrm{UV}$ light, $\mathrm{H}_{2} \mathrm{O}_{2}$, and combinations of these stimuli. These copolymers were self-assembled to form nanoparticles in 
aqueous solution with hydrodynamic diameters ranging from $46-83 \mathrm{~nm}$. Their depolymerization was induced by the respective stimuli and was studied by DLS and NMR spectroscopy. For DTT and $\mathrm{H}_{2} \mathrm{O}_{2}$, depolymerization occurred at a rate dependent on the stimulus concentration, and degradation of the nanoparticles could be detected at concentrations corresponding to less than 2 equiv. relative to the end-cap and less than 0.01 equiv. relative to the polymerization monomer. This confirmed that single end-cap cleavage events could be translated to afford large changes in the systems through depolymerization. The encapsulation and triggered release capabilities of the nanoparticles were also probed using nile red, Dox, and Cur. In each case, the stimulus was capable of selectively releasing the payload. Furthermore, it was demonstrated that the system is highly tunable as the stimulus to which the system responds can be changed by changing only the small molecule linker end-cap between the two blocks. These properties make this new platform highly promising for drug delivery applications. Future work will focus on the in vitro and in vivo evaluation of these nanoparticles.

\section{Acknowledgment}

We thank the Natural Sciences and Engineering Research Council of Canada (Discovery Grant 2016-04636 and Strategic Partnership Grant 478981-15) for funding this work.

\section{Supporting information}


Additional experimental procedures, end-cap cleavage mechanisms, NMR spectra, SEC traces, thermal data, DLS data, NMR depolymerization data, nile red photostability test. This material is available free of charge via the Internet at http://pubs.acs.org.

\section{References}

(1) Mai, Y.; Eisenberg, A. Self-Assembly of Block Copolymers. Chem. Soc. Rev. 2012, 41, 5969-5985.

(2) Kim, J. K.; Yang, S. Y.; Lee, Y.; Kim, Y. Functional Nanomaterials Based on Block Copolymer Self-Assembly. Prog. Polym. Sci. 2010, 35, 1325-1349.

(3) Albert, J. N.; Epps, T. H. Self-Assembly of Block Copolymer Thin Films Mater. Today 2010, 13, 24-33.

(4) Tyrrell, Z. L.; Shen, Y.; Radosz, M. Fabrication of Micellar Nanoparticles for Drug Delivery through the Self-Assembly of Block Copolymers. Prog. Polym. Sci. 2010, 35, 1128-1143.

(5) Rösler, A.; Vandermeulen, G. W. M.; Klok, H.-A. Advanced Drug Delivery Devices Via Self-Assembly of Amphiphilic Block Copolymers. Adv. Drug Delivery Rev. 2012, 64, 270-279.

(6) Movassaghian, S.; Merkel, O. M.; Torchilin, V. P. Applications of Polymer Micelles for Imaging and Drug Delivery. Wiley Interdiscip. Rev.: Nanomed. Nanobiotechnol. 2015, 7, 691-707.

(7) Prabhakar, U.; Maeda, H.; Jain, R. K.; Sevick-Muraca, E. M.; Zamboni, W.; Farokhzad, O. C.; Barry, S. T.; Gabizon, A.; Grodzinski, P.; Blakey, D. C. Challenges and Key Considerations of the Enhanced Permeability and Retention Effect for Nanomedicine Drug Delivery in Oncology. Cancer Res. 2013, 73, 2412-2417.

(8) Maeda, H.; Nakamura, H.; Fang, J. The Epr Effect for Macromolecular Drug Delivery to Solid Tumors: Improvement of Tumor Uptake, Lowering of Systemic Toxicity, and Distinct Tumor Imaging in Vivo. Adv. Drug Delivery Rev. 2013, 65, 71-79. 
(9) Nicolas, J.; Mura, S.; Brambilla, D.; Mackiewicz, N.; Couvreur, P. Design, Functionalization Strategies and Biomedical Applications of Targeted Biodegradable/Biocompatible Polymer-Based Nanocarriers for Drug Delivery. Chem. Soc. Rev. 2013, 42, 1147-1235.

(10) Bachelder, E. M.; Beaudette, T. T.; Broaders, K. E.; Dashe, J.; Fréchet, J. M. Acetal-Derivatized Dextran: An Acid-Responsive Biodegradable Material for Therapeutic Applications. J. Am. Chem. Soc. 2008, 130, 10494-10495.

(11) Chen, W.; Meng, F.; Li, F.; Ji, S.-J.; Zhong, Z. pH-Responsive Biodegradable Micelles Based on Acid-Labile Polycarbonate Hydrophobe: Synthesis and Triggered Drug Release. Biomacromolecules 2009, 10, 1727-1735.

(12) Liu, Y.; Wang, W.; Yang, J.; Zhou, C.; Sun, J. pH-Sensitive Polymeric Micelles Triggered Drug Release for Extracellular and Intracellular Drug Targeting Delivery. Asian J. Pharm. Sci. 2013, 8, 159-167.

(13) Liu, J.; Huang, Y.; Kumar, A.; Tan, A.; Jin, S.; Mozhi, A.; Liang, X. J. pH-Sensitive Nano-Systems for Drug Delivery in Cancer Therapy. Biotechnol. Adv. 2014, 32, 693-710.

(14) Ganta, S.; Devalapally, H.; Shahiwala, A.; Amiji, M. A Review of Stimuli-Responsive Nanocarriers for Drug and Gene Delivery. J. Controlled Release 2008, 126, 187-204.

(15) Cheng, R.; Feng, F.; Meng, F.; Deng, C.; Feijen, J.; Zhong, Z. Glutathione-Responsive Nano-Vehicles as a Promising Platform for Targeted Intracellular Drug and Gene Delivery. $J$. Controlled Release 2011, 152, 2-12.

(16) Ding, J.; Chen, J.; Li, D.; Xiao, C.; Zhang, J.; He, C.; Zhuang, X.; Chen, X. Biocompatible Reduction-Responsive Polypeptide Micelles as Nanocarriers for Enhanced Chemotherapy Efficacy in Vitro. J. Mater. Chem. B 2013, 1, 69-81.

(17) Liu, B.; Wang, D.; Liu, Y.; Zhang, Q.; Meng, L.; Chi, H.; Shi, J.; Li, G.; Li, J.; Zhu, X. Hydrogen Peroxide-Responsive Anticancer Hyperbranched Polymer Micelles for Enhanced Cell Apoptosis. Polym. Chem. 2015, 6, 3460-3471.

(18) de Gracia Lux, C.; Joshi-Barr, S.; Nguyen, T.; Mahmoud, E.; Schopf, E.; Fomina, N.; Almutairi, A. Biocompatible Polymeric Nanoparticles Degrade and Release Cargo in Response to Biologically Relevant Levels of Hydrogen Peroxide. J. Am. Chem. Soc. 2012, 134, $15758-15764$. 
(19) Phillips, S. T.; DiLauro, A. M. Continuous Head-to-Tail Depolymerization: An Emerging Concept for Imparting Amplified Responses to Stimuli-Responsive Materials. ACS Macro Lett. 2014, 3, 298-304.

(20) Fan, B.; Gillies, E. R. Self-Immolative Polymers. Encycl. Polym. Sci. Technol. 2015, 1-35.

(21) Wong, A. D.; DeWit, M. A.; Gillies, E. R. Amplified Release through the Stimulus Triggered Degradation of Self-Immolative Oligomers, Dendrimers, and Linear Polymers. $A d v$. Drug Delivery Rev. 2012, 64, 1031-1045.

(22) Fan, B.; Trant, J. F.; Wong, A. D.; Gillies, E. R. Polyglyoxylates: A Versatile Class of Triggerable Self-Immolative Polymers from Readily Accessible Monomers. J. Am. Chem. Soc. 2014, 136, 10116-10123.

(23) de Gracia Lux, C.; McFearin, C. L.; Joshi-Barr, S.; Sankaranarayanan, J.; Fomina, N.; Almutairi, A. Single UV or near IR Triggering Event Leads to Polymer Degradation into Small Molecules. ACS Macro Lett. 2012, 1, 922-926.

(24) Liu, G.; Wang, X.; Hu, J.; Zhang, G.; Liu, S. Self-Immolative Polymersomes for High-Efficiency Triggered Release and Programmed Enzymatic Reactions. J. Am. Chem. Soc. 2014, 136, 7492-7497.

(25) Lewis, G. G.; Robbins, J. S.; Phillips, S. T. Point-of-Care Assay Platform for Quantifying Active Enzymes to Femtomolar Levels Using Measurements of Time as the Readout. Anal.

Chem. 2013, 85, 10432-10439.

(26) Lewis, G. G.; Robbins, J. S.; Phillips, S. T. Phase-Switching Depolymerizable Poly(Carbamate) Oligomers for Signal Amplification in Quantitative Time-Based Assays. Macromolecules 2013, 46, 5177-5183.

(27) DeWit, M. A.; Beaton, A.; Gillies, E. R. A Reduction Sensitive Cascade Biodegradable Linear Polymer. J. Polym. Sci., Part A: Polym. Chem. 2010, 48, 3977-3985.

(28) Fan, B.; Trant, J. F.; Gillies, E. R. End-Capping Strategies for Triggering the End-to-End Depolymerization of Polyglyoxylates. Macromolecules 2017, DOI: 10.1021/acs.macromol.6b02320.

(29) Sagi, A.; Weinstain, R.; Karton, N.; Shabat, D. Self-Immolative Polymers. J. Am. Chem. Soc. 2008, 130, 5434-5435. 
(30) Liu, G.; Zhang, G.; Hu, J.; Wang, X.; Zhu, M.; Liu, S. Hyperbranched Self-Immolative Polymers (HSIPs) for Programmed Payload Delivery and Ultrasensitive Detection. J. Am. Chem. Soc. 2015, 137, 11645-11655.

(31) Seo, W.; Phillips, S. T. Patterned Plastics That Change Physical Structure in Response to Applied Chemical Signals. J. Am. Chem. Soc. 2010, 132, 9234-9235.

(32) Kim, H.; Mohapatra, H.; Phillips, S. T. Rapid, on - Command Debonding of Stimuli Responsive Cross - Linked Adhesives by Continuous, Sequential Quinone Methide Elimination Reactions. Angew. Chem. Int. Ed. 2015, 54, 13063-13067.

(33) Fan, B.; Trant, J. F.; Yardley, R. E.; Pickering, A. J.; Lagugné-Labarthet, F.; Gillies, E. R. Photocontrolled Degradation of Stimuli-Responsive Poly(Ethyl Glyoxylate): Differentiating Features and Traceless Ambient Depolymerization. Macromolecules 2016, 49, 7196-7203.

(34) DeWit, M. A.; Gillies, E. R. A Cascade Biodegradable Polymer Based on Alternating Cyclization and Elimination Reactions. J. Am. Chem. Soc. 2009, 131, 18327-18334.

(35) Monks, T. J.; Jones, D. C. The Metabolism and Toxicity of Quinones, Quinonimines, Quinone Methides, and Quinone-Thioethers. Curr. Drug Metab. 2002, 3, 425-438.

(36) Baker, P. R. S.; Cramer, S. D.; Kennedy, M.; Assimos, D. G.; Holmes, R. P. Glycolate and Glyoxylate Metabolism in Hepg2 Cells. Am. J. Physiol. Cell Physiol. 2004, 287, C1359-1365.

(37) Belloncle, B.; Bunel, C.; Menu-Bouaouiche, L.; Lesouhaitier, O.; Burel, F. Study of the Degradation of Poly(Ethyl Glyoxylate): Biodegradation, Toxicity and Ecotoxicity Assays. $J$. Polym. Environ. 2012, 20, 726-731.

(38) Nguyen, P. K.; Snyder, C. G.; Shields, J. D.; Smith, A. W.; Elbert, D. L. Clickable Poly(Ethylene Glycol) - Microsphere - Based Cell Scaffolds. Macromol. Chem. Phys. 2013, 214, 948-956.

(39) Liu, Y.; Shipton, M. K.; Ryan, J.; Kaufman, E. D.; Franzen, S.; Feldheim, D. L. Synthesis, Stability, and Cellular Internalization of Gold Nanoparticles Containing Mixed Peptide-Poly(Ethylene Glycol) Monolayers. Anal. Chem. 2007, 79, 2221-2229.

(40) Kuppusamy, P.; Li, H.; Ilangovan, G.; Cardounel, A. J.; Zweier, J. L.; Yamada, K.; Krishna, M. C.; Mitchell, J. B. Noninvasive Imaging of Tumor Redox Status and Its Modification by Tussue Glutathione Levels. Cancer Res. 2002, 62, 307-312. 
(41) Gough, D. R.; Cotter, T. G. Hydrogen Peroxide: A Jekyll and Hyde Signalling Molecule. Cell Death \& Disease 2011, 2, e213.

(42) Gohy, J.-F.; Zhao, Y. Photo-Responsive Block Copolymer Micelles: Design and Behavior. Chem. Soc. Rev. 2013, 42, 7117.

(43) Chung, C.; Srikun, D.; Lim, C. S.; Chang, C. J.; Cho, B. R. A Two-Photon Fluorescent Probe for Ratiometric Imaging of Hydrogen Peroxide in Live Tissue. Chem. Commun. 2011, 47 , 9618-9620.

(44) Harris, J. M.; Martin, N. E.; Modi, M. PEGylation: A Novel Process for Modifying Pharmacokinetics. Clin. Pharmacokinet. 2001, 40, 539-551.

(45) Banerjee, S. S.; Aher, N.; Patil, R.; Khandare, J. Poly(Ethylene Glycol)-Prodrug Conjugates: Concept, Design, and Applications. J. Drug Delivery 2012, 2012, Article ID 103973.

(46) Discher, D. E.; Eisenberg, A. Polymer Vesicles. Science 2002, 297, 967-973.

(47) Gillies, E. R.; Fréchet, J. M. A New Approach Towards Acid Sensitive Copolymer Micelles for Drug Delivery. Chem. Commun. 2003, 1640-1641.

(48) Montero, D.; Tachibana, C.; Winther, J. R.; Appenzeller-Herzog, C. Intracellular Glutathione Pools Are Heterogeneously Concentrated. Redox Biol. 2013, 1, 508-513.

(49) Rothwarf, D. M.; Scheraga, H. A. Equilibrium and Kinetic Constants for the Thiol-Disulfide Interchange Reaction between Glutathione and Dithiothreitol. Proc. Natl. Acad. Sci. USA 1992, 89, 7944-7948.

(50) Funderburk, L. H.; Aldwin, L.; Jencks, W. P. Mechanisms of General Acid and Base Catalysis of the Reactions of Water and Alcohols with Formaldehyde. J. Am. Chem. Soc. 1978, 100, 5444-5459.

(51) Giorgio, M.; Trinei, M.; Migliaccio, E.; Pelicci, P. G. Hydrogen Peroxide: A Metabolic by-Product or a Common Mediator of Ageing Signals? Nat. Rev. Mol. Cell Biol. 2007, 8, $722-728$.

(52) Forman, H. J.; Bernardo, A.; Davies, K. J. A. What Is the Concentration of Hydrogen Peroxide in Blood and Plasma? Arch. Biochem. Biophys. 2016, 603, 48-53.

(53) Greenspan, P.; Mayer, E. P.; Fowler, S. D. Nile Red: A Selective Fluorescent Stain for Intracellular Lipid Droplets. J. Cell Biol. 1985, 100, 965-973. 
(54) Krishna, M. M. G. Excited-State Kinetics of the Hydrophobic Probe Nile Red in Membranes and Micelles. J. Phys. Chem. A 1999, 103, 3589-3595.

(55) Tacar, O.; Sriamornsak, P.; Dass, C. R. Doxorubicin. J. Pharm. Pharmacol. 2012, 65, 157-170.

(56) Salem, M.; Rohani, S.; Gillies, E. R. Curcumin, a Promising Anti-Cancer Therapeutic: A Review of Its Chemical Properties, Bioactivity and Approaches to Cancer Cell Delivery. RSC $A d v$. 2014, 4, 10815-10829.

(57) Priyadarsini, K. I. The Chemistry of Curcumin: From Extraction to Therapeutic Agent. Molecules 2014, 19, 20091-20112. 
For Table of Contents Use Only

Poly(ethyl glyoxylate)-poly(ethylene oxide) nanoparticles: Stimuli-responsive drug release via end-to-end polyglyoxylate depolymerization

Bo Fan and Elizabeth R. Gillies

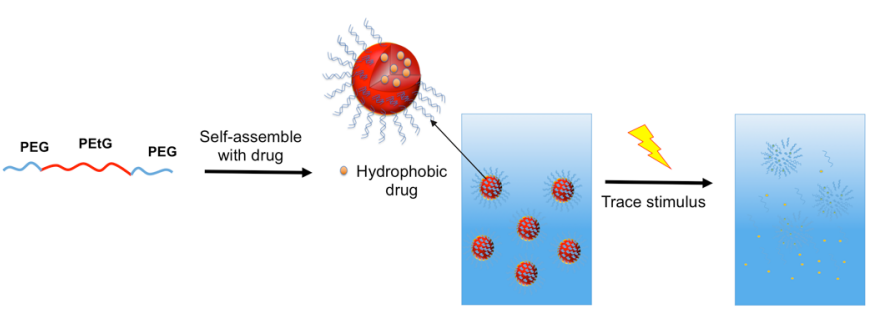

